\title{
Ventricular Assist Devices for Pediatric Heart Disease
}

\author{
Cenk Eray Yildiz \\ Istanbul University, Institute of Cardiology, \\ Department of Cardiovascular Surgery, Istanbul, \\ Turkey
}

\section{Introduction}

Mechanical Circulation Assist Devices are designed for the treatment of acute and chronic heart failure and can be applied for different indications and assist period. Treatments that are carried out with Ventricular Assist Device System (VADs) have improved over course of time, within the practical applications of pediatric cardiac surgery. Pulsatile devices being in the lead, paracorporeal assist devices and implantable ventricular assist devices all have fields of application. However, ECMO (Extracorporeal Membrane Oxygenator) treatment is still applied on infants and children. These systems are preferred to assist patients with respiratory failure after heart surgery. But, this assist remains for a short term and compulsorily puts the patients into intensive care. In recent years, so many new devices have been developed, such as easily intubated cannulas for children including infants and miniature pumps for pediatric use. These devices are recommended for mid and long term, which is more predominant than ECMO. They are applied successfully to assist bridge to recovery and bridge to transplantation. Here, an assessment is made for different types of contemporary devices, decision making and application strategy, device technology, implantation techniques, anticoagulation and follow-up, new generation assist devices that operate with pediatric ventricular assist device for the treatment of pediatric heart failure. Proverbially, in spite of the successful results, ECMO and centrifugal pumps are not suitable for every patient because of the reasons such as long period of stays in intensive care unit, lack of mobilization and shortness of operating time. VAD systems are developed for little children of previously which only ECMO was suitable for. With the VAD treatment of selected pediatric population, especially in the cases of myocarditis and cardiomyopathy, mobilization and low anticoagulation have been enabled and resulted in $90 \%$ of survival rate. VAD is preferred instead of ECMO and if there is a need for circulation assist that exceeds 1-2 weeks, the complication rate decreases. These devices get more reliable day by day and they will play an effective role in future as a treatment method for the complex congenital heart diseases that aim for transplantation or bridging treatment for cardiac recuperation. Eventually, what is dreamt for future is to attain permanent solutions. 


\section{History of mechanical support device in pediatrics}

In 1974 Bartlett reported the use of extracorporeal membrane oxygenation in pediatric patients with respiratory failure or after repair of congenital heart disease. Bartlett first used the ECMO device on a neonate and named it "Esperanza", meaning "Hope" (Bartlett et al., 1977). In 1980 Pollock reported the first use of an intraaortic balloon pump in children (Pollock et al., 1980). In 1983, Veasy reported the use of small balloon catheters in 15 children (Veasy et al., 1983). The Thoratec ventricular assist devices have been available since the early 1980s, and can be implanted in children and adolescents (Reinhartz et al, 2001). The first neonatal oxygenator was released in the 1990s (Duncan, 2001).

In spite of the success of ventricular assist devices for adults, not much has been done to develop similar devices for pediatric population. Afterwards, in 1992, the "Berlin Heart" offered the first commercially available system with miniaturized paracorporeal pumps and cannulae. The first implantation of a Medos ventricular assist device as a bridging to transplantation took place in 1994 (Konertz, 2001). The DeBakey VAD Child (MicroMed Technology, Inc. Houston, TX) became available for use in 2004 (Morales et al., 2005).

In 1989, it was reported by ELSO (Extracorporeal Life Support Organization) that the number of centers that use ECMO was 100 worldwide. Until 2005, more than 30.000 patients, with the support of ECMO, have survived with $65 \%$ success rate (ECLS Registry, 2005). ECLS registry in 2008 provides a database of 37.000 patients from all around the world with details about demographic factors, diagnosis, treatment and complications (Haines et al., 2009). There have been studies with $80 \%$ success for the usage of ECMO on infants with acute hypoxemic respiratory failure (Field et al., 1996). On infants that undergo traditional treatments, the survival rate is $30 \%$. With ECMO support, this rate is doubled (Bennett et al., 2001). Currently, the support devices are applied on infants and children with uncontrollable heart failure. Final ECLS, ECMO guideline has been published in April 2009. In this chapter, we will be discussing ECMO as a cardiac support device and as well as other mechanical cardiac support devices applied on child patients.

\section{The selection of mechanical support devices}

The selection of suitable mechanical support device is determined according to the surface area of the body. Mechanical support indication depends on the predetermining the length of time between bridging treatment and transplantation, effect of the disease, pathophysiological events and the fact that many organizations can obtain different devices. Although there have been a variety of cardiac support systems for adult patients, the devices for neonates and infants are scarce. Today, two of the the most common methods for the short term cardiac support for infants are ECMO and Centrifugal Extracorporeal VAD (Ventricular Assist Device) (Table 1). Nowadays, the presence of new paracorporeal VAD is encouraging. The technical specifications of mechanical cardiac devices used for children are summarized in Table 2. These systems are used in bridging treatment that extends the transplantation period a few months. Since the case is completed, intra-aortic balloon pump (IABP) will be discussed, although it is rare for pediatric patients.

\subsection{Extracorporeal membrane oxygenation (ECMO)}

ECMO is the most important assist system for mechanical heart support for pediatric population. There are two major methods: veno-venous ECMO, which provides ventilator 


\begin{tabular}{|l|l|l|}
\hline & \multicolumn{1}{|c|}{ ECMO } & \multicolumn{1}{c|}{ VAD } \\
\hline Oxygenator & Yes & No \\
\hline Circulation & Long, with reservoir & Short, no reservoir \\
\hline Anticoagulation & ACT 180-220 seconds & ACT 140-160 seconds \\
\hline Air emboli & Low & High (L-VDC) \\
\hline Support type & Cardiorespiratory & Cardiac \\
\hline Ventricular decompression & Atrial septestomy/LA vent & Not required \\
\hline Length of Support & A few weeks & Weeks \\
\hline Cannulation & Transthoracic or jugular & Transthoracic \\
\hline
\end{tabular}

Table 1. Comparison of ECMO and centrifugal extracorporeal VAD

\begin{tabular}{|c|c|c|c|c|c|c|c|c|}
\hline $\begin{array}{l}\text { Device } \\
\text { type }\end{array}$ & $\begin{array}{c}\text { Intra- } \\
\text { aortic } \\
\text { baloon } \\
\text { pump }\end{array}$ & ECMO & $\begin{array}{l}\text { Centri- } \\
\text { fugal } \\
\text { pump }\end{array}$ & $\begin{array}{l}\text { Berlin } \\
\text { Heart } \\
\text { Excor }\end{array}$ & \begin{tabular}{|c|} 
Medos \\
HIA VAD
\end{tabular} & $\begin{array}{c}\text { Thoratec } \\
\text { II }\end{array}$ & $\begin{array}{c}\text { HeartMate } \\
\text { IP/VE }\end{array}$ & $\begin{array}{l}\text { Abiomed } \\
\text { BVS 5000 }\end{array}$ \\
\hline Position & Intraaortic & External & External & External & External & External & External & External \\
\hline $\begin{array}{l}\text { Ventri- } \\
\text { cular } \\
\text { support }\end{array}$ & Left & Double & $\begin{array}{l}\text { Left, } \\
\text { right or } \\
\text { double }\end{array}$ & $\begin{array}{l}\text { Left, } \\
\text { right or } \\
\text { double }\end{array}$ & $\begin{array}{l}\text { Left, } \\
\text { right or } \\
\text { double }\end{array}$ & $\begin{array}{l}\text { Left, } \\
\text { right or } \\
\text { double }\end{array}$ & Left & $\begin{array}{l}\text { Left, } \\
\text { right or } \\
\text { double }\end{array}$ \\
\hline Duration & Short & Short & Short & Long & Short & $\begin{array}{l}\text { Medium } \\
\text { Long }\end{array}$ & Long & Medium \\
\hline Flow & Pulsatile & $\begin{array}{c}\text { Non - } \\
\text { pulsatile }\end{array}$ & $\begin{array}{c}\text { Non - } \\
\text { pulsatile }\end{array}$ & Pulsatile & Pulsatile & Pulsatile & Pulsatile & Pulsatile \\
\hline $\begin{array}{l}\text { Power } \\
\text { Supply }\end{array}$ & Pneumatic & Electrical & Electrical & Pneumatic & Pneumatic & Pneumatic & $\begin{array}{c}\text { Electrical } \\
\text { or } \\
\text { Pneumatic }\end{array}$ & Pneumatic \\
\hline $\begin{array}{l}\text { Cannu- } \\
\text { lation }\end{array}$ & $\begin{array}{c}\text { Peripheric } \\
\text { Artery }\end{array}$ & $\begin{array}{c}\text { Peripheric } \\
\text { Artery } \\
\text { and Ven }\end{array}$ & $\begin{array}{l}\text { Central } \\
\text { or Peri- } \\
\text { pheric }\end{array}$ & Central & Central & $\begin{array}{l}\text { Central or } \\
\text { Peripheric }\end{array}$ & Central & Central \\
\hline $\begin{array}{l}\text { Anticoa- } \\
\text { gulation }\end{array}$ & $\begin{array}{l}\text { Not } \\
\text { required }\end{array}$ & Required & $\begin{array}{l}\text { Not } \\
\text { required } \\
\text { or low }\end{array}$ & Required & Required & Required & $\begin{array}{l}\text { Not } \\
\text { required }\end{array}$ & Required \\
\hline $\begin{array}{l}\text { Mobili- } \\
\text { zation }\end{array}$ & No & No & No & Yes & No & $\begin{array}{c}\text { Yes, } \\
\text { limited }\end{array}$ & No & No \\
\hline $\begin{array}{c}\text { Discharge } \\
\text { from } \\
\text { hospital }\end{array}$ & No & No & No & No & No & Yes & Yes & No \\
\hline
\end{tabular}

Table 2. Technical specification of mechanical cardiac assist devices for pediatric patients

support and the other one is veno-arterial ECMO, which is suitable for patients with circulatory failure and it provides both heart and lung support. ECMO is more advantageous than other devices in terms of its usage for patients with bi-ventricular failure, respiratory insufficiency and pulmonary hypertension. Discharge survival rate of a short 
term ECMO treated patient is $40-80 \%$ (Bartlett et al., 1977). If the recovery time is prolonged, risk of infection increases. Since there is a complication incidence, the usage of ECMO is limited within a few feeks (max. 4-6 weeks) (Cahturvedi et al., 2004). For the patients that require a longer assistance, other types of ventricular assist devices may be suitable.

Reports of a center's experience usually find that conditions of complex heart disease with either excess pulmonary blood flow or decreased pulmonary blood flow constitute the majority of cases requiring ECMO for pediatric cardiac support (Duncan et al., 1999). The most common scenarios for support usually occur in children after cardiac surgery, namely, failure to wean from cardiopulmonary bypass and cardiogenic shock or cardiac arrest occurring in the intensive care unit postoperatively (Delius et al., 1992; Hunkeler et al., 1992; Raithel et al., 1992). However, nonresponsive medical conditions also occur in children that require mechanical circulatory support (Duncan et al., 2001; Del Nido et al., 1994). Conditions that represent contraindications for ECMO are now often successfully supported. For instance, patients with shunted single ventricle physiology, were often denied ECMO in the past due to difficulties in achieving balance between the pulmonary and systemic circulations. Due to improvements, ECMO and VADs are currently necessary adjuncts for the successful surgical approach to these patients (Darling et al., 2001; Pizarro et al., 2001).

Since its launch, ECMO has been the predominant form of support for children. Due to the presence of an oxygenator in the circuit, ECMO is most useful in providing support when heart disease is accompanied by hypoxia and pulmonary hypertension. The presence of an oxygenator and other complexities of the ECMO circuit require higher levels of anticoagulation (Hetzer et al., 1998).

Another important difference between devices is the impact on recovery of ventricular function during support. Experimental studies have shown increased ventricular wall stress during ECMO support while VADs provide better ventricular unloading leading to decreased wall stress (Ratcliffe et al., 1991). ECMO may also contribute to ongoing myocardial damage during support by providing desaturated blood flow to the coronary arteries (Kato et al., 1996). ECMO provides only short-term support, requires intensive nursing management, and is not suitable for ambulatory support. ECMO support is limited to a few weeks; after this time period, multi-system organ failure ensues, probably due to chronic activation of the inflammation that occurs during ECMO support.

\subsection{Centrifugal pump VAD}

Centrifugal pump systems, such as the Bio-Pump (Medtronic Bio-Medicus, Minneapolis, $\mathrm{MN}$ ), are the most commonly used form of VAD support for children. Such VADs provide non-pulsatile flow. The centrifugal VAD circuit employs short tubing lengths to connect the pump to the venous and aortic cannulas, which reduces priming volumes compared to ECMO and makes the system easy to maintain(Karl \& Horton, 2001). Heparin requirements as well as trauma to blood elements may be decreased with Bio-Pump-based VAD circuits owing to the absence of an oxygenator or venous reservoir. Despite its simplicity and proven track record, the main limitation for the Bio-Pump VAD, like ECMO, is its unsuitability for prolonged support. Thus reported excellent results using the Bio-Pump to support infants and children weighing $6 \mathrm{~kg}$ or less (Thuys et al., 1998). Utilizing this system, the authors supported 34 children with median age of 2 months (range $0-8$ months) and weight of $3.7 \mathrm{~kg}$ (range 1.9-5.98 kg). Of 34 supported, $63 \%$ were successfully separated from VAD support and $31 \%$ of this difficult patient population survived to hospital discharge. 
Other reports have described the utility of centrifugal VAD to support the entire spectrum of pediatric cardiac disease (Langley et al., 1998).

\subsection{Ventricular assist devices (VADs)}

Nonpulsatile centrifugal VADs are used for effective assistance, after a congenital heart surgery of neonates and infants that develop ventricular incompetence. They can be applied especially on patients who will undergo heart transplantation following anomalous origin of the left coronary artery from the pulmonary artery repair or late arterial switch operation and secondary pulmonary hypertension in right heart failure (Del Nido et al., 1999). Discharge survival rate in two studies supported by peroperative centrifugal VAD is around $40 \%$ and have similarities with the usage of ECMO (Duncan et al., 1999; Thuys et al., 1998).

The biggest advantage of centrifugal VAD usage is simplicity of this circulation device. It provides better ventricular decompression than ECMO and does not require oxygenation and requires very low anticoagulation. Although, the usage of biventricular devices on neonates and infants is not realistic, the number of devices is only a few and it requires four cannulas and two pumps. The usage of univentricular VAD is not suitable for patients with resistant respiratory failure, pulmonary hypertension and large intracardiac shunt. It may be used for a few weeks for short term support. The main characteristics of ECMO with centrifugal VAD system are shown on Table 1. There are various devices with long term mechanical support, such as, from paracorporeal VADs to impeller pumps. One of the two paracorporeal VADs, commonly used for neonates and infants is Excor pediatric from Berlin Heart AG and the other is Medos HIA. These are pneumatic devices that work with pulsatile flow. These pumps have different types that can operate on stroke volume under $10 \mathrm{ml}$ for neonates (Merkle et al., 2003; Reinhartz et al., 2002). Thoratec paracorporeal assist devices can be used successfully for adult patients and child patients over 10 years of age, as well (Reinhartz et al., 2001).

Paracorporeal assist devices have been applied on patients with cardiomyopathy or myocarditis for bridging to transplantation. Some patients have been assisted over 100 days, by being extubated and mobilized in the hospital. The usage of these devices for postcardiotomy syndrome is limited and the results are poor. There is a risk of hemorrhagic and thromboembolic stroke in VADs and various neurologic problems may occur (Merkle et al., 2003; Reinhartz et al., 2001).

There are some advanced devices with long term mechanical support in many centers such as DeBakey from Micromed, Jarvik and Incor from Berlin Heart AG that have been produced under the description, impeller axial flow pumps (Song et al., 2003). Today, pediatric version of the DeBakey pump is used and it is still too early to speculate on the success of this pump in pediatric population. Though they have an effective use, only some certain pediatric VADs are approved by FDA (Table 3).

In the United States, several FDA-approved options are available for bridging the patient to recovery and transplantation. These options include the following:

1. Abiomed BVS 5000 circulatory support system (Abiomed, Inc, Danvers, Mass), which is typically used for short-term support

2. Abiomed AB5000 circulatory support system (Abiomed, Inc)

3. Centrimag or Levitronix system (Thoratec, Pleasanton, Calif)

4. Thoratec paracorporeal and intracorporeal LVAD and RVAD (Thoratec)

5. Novacor LVAD (World Heart Inc, Oakland, Calif)

6. HeartMate I LVAD (Thoratec) 


\begin{tabular}{|l|l|l|l|}
\hline Device & Brand & Weight of patient & Pump type \\
\hline Heart mate LVAD & Thoratec & BSA $>0,7 \mathrm{~m}^{2}$ & Pusher Plate \\
\hline Thoratec VAD & Thoratec & BSA $>0,7 \mathrm{~m}^{2}$ & Pusher Plate \\
\hline Abiomed BVS 5000 & Abiomed & BSA $>0,7 \mathrm{~m}^{2}$ & Axial \\
\hline DeBakey VAD & Micro Med Tech. & BSA $0,7-1,5 \mathrm{~m}^{2}$ & Axial \\
\hline Excor pediatric* & Berlin Heart & $>2,4 \mathrm{~kg}$ & Pusher Plate \\
\hline
\end{tabular}

Table 3. Federal Drug Administration (FDA) approved, ventricular assist devices, suitable for children. (BSA: Body Surface Area, *Can be used for life-threathening conditions, by authorization.)

\subsection{Intra-aortic balloon pump (IABP)}

The main purpose of intra-aortic balloon pump is to lower the left ventricular afterload of patients with resistant left ventricular failure and to increase coronary perfusion. Balloon is positioned on the descending thoracic aorta. It is filled with helium during diastole, increasing the coronary blood flow. At the beginning of the systole, the balloon is deflated, left ventricular afterload decreases and eventually, cardiac output increases. Although, a sutiable balloon size is available for infants and little children, peripheral vascular complications related to mesenteric extremity ischemia may still occur (Akomea-Agyin et al., 1999). It is hard for the balloon to get in sync on children with high heart rate. There have been many experiences about the usage of IABP on adult patients. However, they are not used in routine practice for infants and little children. IABP may have a role on the treatment of adolescent children with left ventricular failure before placing a different mechanical assist device other than ECMO.

\section{Heartmate, Thoratec and the ABIOMED BVS 5000}

Several groups have successfully provided mechanical circulatory support for older children utilizing systems designed primarily for adult applications The use of the Heartmate VAD (Thoratec Corp., Pleasanton, CA) in 12 adolescent patients was described. Most of these patients had idiopathic dilated cardiomyopathy. The relatively older age of these patients (range 11-20 years) and larger size (body surface area range $1.4-2.2 \mathrm{~m}^{2}$ ) allowed the use of this device. As in the adult experience, the majority of children supported by the vented electric model were discharged home with resumption of normal activities (McBride et al., 1999; Korfer at al., 2000).

A number of reports exist describing experience with the Thoratec VAD (Thoratec Corp., Pleasanton, CA) in children. In Reinhartz's review, 101 pediatric patients [median age 13.7 years (range 7-17 years), median weight $54 \mathrm{~kg}$ (17-110 kg), median body surface area $1.5 \mathrm{~m}^{2}$ (range 0.7-2.2 $\mathrm{m}^{2}$ )] had undergone support with the Thoratec VAD worldwide with $66 \%$ survival to hospital discharge (Akomea-Agyin et al., 1999).

Ashton and et al. employed the ABIOMED BVS 5000 (ABIOMED, Inc., Danvers, MA) in four older children. The ABIOMED device was used to provide temporary circulatory support for patients with a body surface area greater than $1,2 \mathrm{~m}^{2}$ with flows greater than $2 \mathrm{~L} / \mathrm{min}$. A particular limitation to more widespread pediatric application of devices designed primarily for adults can be attributed to low pump rates during support for all but the largest children limiting pump wash-out leading to increased thromboembolic risk (Ashton et al., 1995). 


\section{MEDOS HIA VAD and the Berlin Heart}

The MEDOS HIA VAD (MEDOS Medizintechnik AG, Stolberg, Germany) and the Berlin Heart VAD (Berlin Heart AG, Berlin, Germany) are paracorporeal pulsatile pediatric VAD systems. Because the systems are available in a variety of pump sizes $(10-80 \mathrm{ml})$, they are suitable for the entire age range of pediatric patients including neonates (Shum-Tim et al., 1997). Both are paracorporeal systems that employ pneumatically driven, flexible blood sac pumps, to provide pulsatile flow. Inlet and outlet valves are tri-leaflet and constructed from polyurethane in the smallest versions.

Both the MEDOS and Berlin Heart systems are superior to ECMO in providing moderate to long-term support and preserve the options of bridging to transplantation or recovery for children. Also unlike ECMO, both of these systems allow extubation and ambulation during support with the same effects provided by similar systems designed for adults. Several series have been published describing use of the MEDOS system for pediatric support. Reinhartz reported 64 children supported with the MEDOS HIAVAD, $44 \%$ of whom were supported with the smallest pump sizes with an overall survival of $38 \%$ for patients with available follow-up (Reinhartz et al., 2002). The Berlin Heart VAD has fewer bleeding complications compared to ECMO with decreased blood product utilization during support (Stillert et al., 2004). A recent report showed improving results for infant support in the latest group of patients with survival rates now approaching those achieved in adults (Stiller et al., 2005).

\section{The MicroMed DeBakey VAD child (Heart Assist 5)}

The DeBakey VAD Child (MicroMed Technology, Inc. Houston, TX) became available for use in 2004. This pediatric device employs the same axial-flow pump used in the adult version with design modifications aimed at reducing the lateral space requirements for device implantation. These design modifications include a shortened inflow cannula with a more acute angle for the inflow tubing, a shortened plastic outflow graft protector and reduced size of the flow probe on the outflow graft. Under the current Humanitarian Device Exemption (HDE), the VAD Child is used to provide temporary left ventricular support as a bridge to cardiac transplantation for children from 5 to 16 years of age with a BSA $>0,7 \mathrm{~m}^{2}$ and $<1,5 \mathrm{~m}^{2}$ and is designed to be fully implantable in this size range. Although the clinical experience is still limited, this device has been used successfully in a number of children since its introduction (Morales et al., 2005).

\section{Current and future developments pediatric circulatory support devices}

The clear need for better means to chronically support the circulation in infants and children with congenital and acquired heart disease resulting in severe heart failure has stimulated recent efforts to develop these much needed devices. The development of these devices is being funded by government agencies, industry, and institutions. The National Heart, Lung, and Blood Institute currently supports the development of pediatric circulatory support devices (Table 4). The program and the devices being developed through NHLBI support are described below;

1. The PediaFlow (University of Pittsburgh; Carnegie Mellon University; Children's Hospital of Pittsburgh; LaunchPoint, LLC; and World Heart Corporation) 
2. pCAS (Ension, Inc. University of Louisville; Seare Biomatrix Systems; Fluent, Inc.)

3. Infant- and Child-size Jarvik 2000 (Jarvik Heart, Inc.; University of Maryland Medical Center; Mississippi State University; Whalen Biomedical, Inc.)

4. Penn State PVADs (Penn State University; Minnetronix, Inc.)

5. PediPump (The Children's Hospital at the Cleveland Clinic; The Department of Biomedical Engineering, The Cleveland Clinic Foundation; Foster-Miller Technologies, Inc.)

\subsection{Other NHLBI-supported research}

1. Pediatric pVAD (CardiacAssist)

2. CardioFlowPQ (Ension)

3. Miniature MagLev VAD (Levitronix)

4. Toddler VAD (Pittsburgh/Carnegie-Mellon University)

5. Fetal Perfusion System (Ension, Inc.)

\begin{tabular}{|l|l|l|}
\hline Device & Research Institute & Pump type \\
\hline PediaFlow VAD & University of Pittsburgh & Axial \\
\hline PediPump & Cleveland Clinic & Axial \\
\hline PCAS & Ension, Inc, U Louisville & Centrifugal \\
\hline Pediatric Jarvik 2000 & Jarvik Heart, U Maryland & Axial \\
\hline PVAD & Penn State University & $\begin{array}{l}\text { Pneumatic pulsatile } \\
\text { pusher plate }\end{array}$ \\
\hline RotaFlow & Jostra & Centrifugal \\
\hline PediVAS & Levitronix & Centrifugal \\
\hline TinyPump & Tokyo University & Centrifugal \\
\hline Maglev Pump & Levitronix & Centrifugal (magnetic) \\
\hline TandemHeart & $\begin{array}{l}\text { CardiacAssist, } \\
\text { Inc.(Pittsburgh) }\end{array}$ & Centrifugal \\
\hline
\end{tabular}

Table 4. Pediatric VADs in development under the NHLBI pediatric circulatory support program (current and future)

\section{Patient selection criteria}

With the development of new mechanical devices and the increase in ECMO usage, criteria for device usage have improved continuously. Therefore, patient selection cirtieria has become far more important.

- Progression of the disease in spite of high-dose traditional treatment.

- If the purpose is not bridging to transplantation with mechanical support, heart and/or pathophysiology is potentially reversible.

- The hemodynamics is important. Corrective surgery must be conducted and the residual lesion must be defined. Otherwise the presence of an undefined defect may risk the possibility of minimal recuperation and hemodynamic recovery. The detailed postoperative evaluation, ecocardiography, heart catheterization, computerized tomography or magnetic resonance are all of vital importance for the patient. 
- The patient must not face with other complications in the intensive care unit. For instance, if there is a cerebral hemorrhage where anticoagulation is contraindicated or if there is a neurologic damage due to hypoxic ischemic encephalopathy, the intensive care support must continue. With a practical point of view, it is not always possible to evaluate the neurological functions of the patient.

In these circumstances, if there is any skepticism about the benefits of the support for the patient, the mechanical support must come to an end, right after neurological function tests. This decision depends on the expectations of the patient's family.

\section{The purpose of using mechanical support devices}

The main purpose is to provide with suitable physiological environement and time for myocardial recuperation by transferring oxygen to the vital organs, when traditional drug treatment fails. Therefore, stress and myocardial oxygen consumption across the ventricular wall will decrease and adequate coronary perfusion will be provided.

The aim of mechanical cardiac support is to help recover from myocardial failure with effects on heart transplantation and even bridging. Ventricular assist devices and all other new designs are used for pediatric population with the aim of destination therapy.

\section{Timing and indications for mechanical support}

There are 3 groups for pediatric mechanical cardiac indications:

1. Patients who develop postcardiotomy syndrome

2. Patients with circulatory failure due to myocarditis and cardiomyopathy

3. Patients with heart failure that develops secondary to sepsis pressure (In this section, this will not be discussed with details, but these mechanical support devices have 50-60 $\%$ success rate.) (Goldman et al., 1997).

\subsection{Postcardiotomy circulatory failure}

Mechanical assist devices are sometimes required for pediatric patients with structural heart disease following a heart surgery. Imflammatory response to cardiopulmonary bypass, direct myocardial damage due to surgery, myocardial ischemia due to aortic cross clemp time and reperfusion damage and eventually myocardial dysfunction caused by myocardial exhaustion with postcardiotomy syndrome develop. The repair of anatomic residual lesions that causes circulatory failure is of vital importance. On the other hand, mechanical support indication is low for postcardiotomy patients with malign arrhythmia and resistant pulmonary hypertension.

For the selection of the correct time for starting mechanical support, the risk of organ failure, which depends on the length of time that the patient is going through an invasive treatment like ECMO, must be taken into account. However, ECMO's oxygenation index does not have effective results for preventing a severe disease. With this sensitivity, there are some approaches for the timing of mechanical support in different centers. In spite of suitable vasoactive drug treatment, so many centers activate the postoperative mechanical support with the deterioration of clinical symptoms of oxygen transfer (increase of lactate, decrease of mixed venous oxygen saturation, peripheral cooling, oliguria and other syptoms of endorgan ischemia). In order to avoid organ damage during low cardiac output period, some centers start mechanical support without waiting for the response of drug treatment, due to 
their concern for myocardial damage that is related to usage of high doses of epinephrine (Reinhartz et al., 2001). Another point of view is that, in spite of the increase of inotropic support (approx. 0,3 microgram $/ \mathrm{kg} / \mathrm{min}$ dose of epinephrine), the mechanical support must be activated due to deteriorating symptoms of low cardiac support. Some centers recommend the usage of VAD in semi effective conditions for postcardiotomy patients who develop severe left ventricular failure after ALCAPA (anomalous left coronary artery from the pulmonary artery) procedure and arterial switch operation (survival rate is $90 \%$ ) (Del Nido et al., 1999; Kang et al., 2004).

Some other centers support the usage of VAD, after Norwood Stage 1 operation. Thereby, within 48 hours of the surgery, the patient is protected from the risk of possible neurological disease in later stages by maintaining the brain oxygenation. Another center did not defend mechanical support after Norwood stage 1 operation, in spite of $80 \%$ survival rate that was reported in the very early reviews. While the short term benefit of this support kept out of view, neurological disease must be monitored for long term (Chaturvedi et al., 2004). In another report, while distinguishing a patient with a failure from cardiopulmonary bypass, morbidity and mortality increase, like hemorrhage, was detected (Duncan et al., 1999).

In univentricular and biventricular anatomy, mechanical support indication is related with reversibility potential of myocardial dysfunction, rather than cardiac anatomy as a result. Therefore, patients with single ventricular function may undergo operation, surgical treatment of complex heart lesions would become possible and reversibility potential is maintained with mechanical support indication.

\subsection{Circulatory failure due to myocarditis and cardiomyopathy}

In popular belief, while heart failure due to cardiymyopathy is a long term disease, myocardial failure on pediatric patients diagnosed with myocarditis, is a fulminant disease that explodes suddenly. Although there are major differences in these two diseases, it is nearly impossible to specify them. It is not always possible to get a diagnosis with myocardial biopsy. It is possible to disconnect the patients with long term cardiomyopathy who require transplantation with signs of acute deterioration, from mechanical support. The importance of the mechanical support and the patients with myocarditis is not rare among some surgeons. Therefore, the mechanical support for these two groups of patients with acute heart failure is suitable. The main purpose of the support is bridging treatment.

The most suitable period for the timing of the mechanical support for these patients is the same with postcardiotomy patients. Development of arryhtmia, intolerance to enteral nutrition and oliguric renal failure are usually bad news. By taking precautions, the wellbeing of the patient must be assured in semi-elective circumstances.

At the end of the first week, if the ventricular function deteriorates, the main purpose must be bridging to transplantation. In this case, long term (monthly) support machines must be considered.

\section{Emergency ECMO or extracorporeal cardiopulmonary resuscitation (ECPR)}

For patients with, severe problems after a long term cardiac arrest, extracorporeal cardiopulmonary resuscitation (ECPR) is highly recommended for high risk of neurological damage. The succesful results of ECMO placement during cardiac arrest have been reviewed many times recently and have a survival rate of $40 \%$ (Duncan et al., 1998; Morris et al., 2004). The patients who have suffered due to cardiac arrest longer than 60 minutes, 
continue their neurological life. The results of neurological studies for these patients are important, as these studies prove that they deserve a life in future. The lifesaving effect of ECPR program is that, the surgeon and the surgical nurse are required to have sufficient knowledge, education and cannulation skills for ECMO circulation. So, many centers must have specialists with ECMO experience in their intensive care unit, as an alternative approach. The latest studies show that if crystalloid solution applied with ECMO properly, circulatory support for more than 2 weeks can be maintained (Karimova et al., 2005). ECPR can be improved by this method. It can be stressful to opt for ECMO as a last option for patients with cardiac arrest. With strategic assessments performed under all circumstances, ECMO can be preferred as an early response.

\section{Practical point of view for mechanical support}

\subsection{Cannulation}

Veno-arterial ECMO for pediatric patients is performed by inserting cannula into the carotid artery (right carotid artery and right internal jugular vein and femoral vein cannulation) or by surgical procedure of median sternotomy. ECMO cannulation technique for neonates which was introduced by Karl in 1990, allows the preservation of carotid and jugular vessels (Karl et al., 1990). Silastic vessel-loop technique provides adequate hemostasis during ECMO cannulation and allows the reconstruction of the vessels during decannulation.

In patients in whom separation from cardiopulmonary bypass is difficult, further support with ECMO may be useful and aorta and right atrium must be prepped for cannulation. Left atrial vent is placed in some patients where necessary. Postcardiotomoy patients who are undergoing or about to undergo cardiac arrest must be urgently provided with cannulation. If there is enough time and no contraindications, carotid cannulation must be performed. In this way, the risk of infection and bleeding will be minimized.

In an aortic valve failure and impaired left ventricular function, it is important that the left heart must be decompressed. In these circumstances, the pressure of left atrium increases (above $30 \mathrm{mmHg}$ ) and lung congestion develops. Left ventricular diastol pressure increases the ventricular wall stress and coronary perfusion deteriorates. Decompression of the left ventricle can be achieved in catheterization laboratory by atrial connection and by direct placement of the left ventricle.

\subsection{Bleeding control}

Severe bleeding is one of the most important complications of postoperative cardiac ECMO. If the bleeding starts unexpectedly, severe blood transfusion will be required. With the deterioration of the coagulopathy, bleeding increases more.

The following are necessary for the control of postcardiotomy bleeding;

- Improving coagulopathy rapidly (giving thrombocyte transfusion until thrombocytes > 100.000 and cryoprecipitate until fibrinogen $>2 \mathrm{gl} / \mathrm{l}$ )

- Keeping activated clotting time (ACT) level between 160-180 seconds (In early stages, it is recommended that activated partial thromboplastin time (aPTT) level must be between $60-80$ seconds. The effect of heparin and coagulation ii determined by heparin level, activated factor $X$ and thromboelestogram)

- Application of antifibrinolytic agents (Aprotinin)

- If bleeding continues inspite of improvement of coagulopathy (>10 ml/ kg/sec), the thorax might be opened again. 
- Opting for carotid cannulation at the neck

- Using the cell-saver device.

- If the bleeding still continues, heparin needs to be cut off within 4-6 hour period until bleeding is stopped (A back-up ECMO circuit must be available at all times).

- In recent years, the usage of recombinant factor VII has been put forward for postcardiotomy patients with resistant bleeding. But routine usage of this treatment is yet to be recommended until the effects are tested by random studies (PychynskaPokorska et al., 2004).

\section{Mechanical support complications}

There are 4 important complications about the usage of cardiac ECMO by ELSO (Extracorporeal Life Support Organization) (Bartlett et al., 1977):

- $30 \%$ bleeding

- $\quad$ Risk of infection (about $30 \%$ )

- Cerebral hemorrhage and infarct (6\% in little children and $12 \%$ in neonates)

- Pump, oxygenation or circulatory failure (10\%)

The most important complications of paracorporeal devices are cerebral symptoms (hemorrhage and thromboembolia) infection and must be diagnosed in the early stages.

\section{Efficiency of ECMO}

For the assessment, end organ perfusion markers must be checked. Acid-base equilibrium, lactate and mixed venous oxygen saturation, urine output are also put into assessment. The most suitable ECMO flow that enables ventricular improvement is usually $200 \mathrm{ml} / \mathrm{kg} / \mathrm{sec}$. The minimum flow that decompresses the ventricle and provides the oxygen transfer may also be favoured.

In oxygen deficiency, hematocrit level must be around $40 \%$ and blood must be separated from oxygenator and adequate oxygen saturation must be maintained. The blood flow can be measured by ultrasonic assessment of the distal section that contains the real blood flow that enables the re-circulation of the patient and which is a bridge to arterial ECMO line. When the real blood flow of the device cannot be measured, bridge to circulation must be clamped and roller pump must be controlled. If symptoms of circulatory failure still occur in spite of these manouvers, there must be an increase in the demand of pump flow for the metabolic needs of the patient. Even at the high flow rate $(>200 \mathrm{ml} / \mathrm{kg} / \mathrm{sec})$, end-organ circulation may not be maintained. In order to decrease the metabolic requirements of the patient, $34{ }^{\circ} \mathrm{C}$ perfusion might be considered. Vasodilatory drugs can be used to control hypertension while afterload is reduced within necessary intervals. Centrifugal pumps are very important in terms of reducing the afterload and maintaining high volume (Right atrial pressure $>5 \mathrm{mmHg}$ ).

\section{The use of ECMO for patients with systemic-pulmonary shunt}

On patients with Blalock-Taussig shunt (BT shunt) who has undergone Norwood Stage I procedure, the use of VADs is favoured. It can be applied on circumstances where there is no lung problem (Ungerleider et al., 2004). It has been claimed that VAD flow must be at high volume (around $200 \mathrm{ml} / \mathrm{kg} /$ minute) in order to provide adequate systemic perfusion 
and compensate the patients with shunt. On these patients, if ECMO is applied, shunt thrombosis or pulmonary infarction may occur (Jaggers et al., 2000).

The patients who are going through Norwood procedure Stage I with Sano modification, are in need of mechanical support. Here, they require ECMO, rather than VAD. Because, in this physiology, adequate blood flow may not be available in the lungs. In this case, an oxygenator is a must.

\section{The follow-up of the patients with mechanical support}

There are various physiological approaches; enteral nutrition, a little sedation, the care of the patient's relatives are important. ECMO ventilation must be adjusted according to the resting mode.The tidal volume must be $5-10 \mathrm{ml} / \mathrm{kg}$ (highest inspiration pressure to be 25 $\mathrm{cmH}_{2} \mathrm{O}$ ), PEEP to be $7-10 \mathrm{cmH}_{2} \mathrm{O}$ and ventilation rate to be $15-20 / \mathrm{min}$. In order to avoid pulmonary desaturation, $\mathrm{FiO}_{2}$ ventilator must be adjusted to $40 \%$. Unlike ECMO, patients with VAD, full ventilation is compulsory. Antibiotics are not routinely necessary for patients with ECMO. However, daily blood culture monitoring and starting the treatment with the presence of an infection are acceptable approaches.

\section{Separation from ECMO (Weaning)}

One of the difficulties of ECMO is not being able to determine the clues of ventricular improvement that allows the separation from cardiac mechanical support unit. Practically, the paitent is laid to rest for 48-72 hours, with ECMO support. Later, inotropic perfusiom application (adrenaline or dopamine, combined with milrinone), left atrial vent is clamped and device flow speed is is decreased gradually within two hours until the lowest safe flow is maintained (100-200 ml/minute). However, due to risk of coagulation ECMO flow must not be reduced below this level. If the flow is reduced successfully without risking the hemodynamics, the patient is ready to separate from the ECMO. In this 2-3 hour period, the patient tries to separate from ECMO and then the patient is decannulated. Ecocardiography is used for the evaluation of the ventricular functions. Besides, complications such as, undiagnosed lesions, pulmonary hypertension, akinesia, dyskinesia, pericardial effusion must be re-assessed. If a failure occurs during the separation from ECMO, this is due to inefficiency of the oxygen transfer to the tissues and hemodynamic disturbance. Therefore ECMO support must be re-started immediately and must wait for another 48 hours. This period is best for ventricular recovery and improvement.

\section{When to end the mechanical support?}

In mechanical support, healing process depends on available pathology. In postcardiotomy patients, myocardial stunning is the basis (Aharon et al., 2001). According to Duncan's suggestion, if signs of ventricular improvement do not occur in this period, the patients must be put on the early transplant list. The timing depends on the organ availability. The separation from mechanical support of the patient who will not undergo transplantation after showing effective signs of cardiac recovery is very important. Survival time with ECMO support is maximum 10 days (Reinhartz et al., 2001; Chaturvedi et al., 2004). In spite of surviving patients who had mechanical support for more than 250 hours, recovery expectancy is highly low for patients who remained under ECMO support for more than 10 
days (Morris et al., 2004). After 2 weeks of mechanical support on a patient who is not a transplant candidate, if there are no signs of improvement of ejection fraction, mechanical support must be suspended, according to the practical approach.

One of the most common problems faced with during cardiac ECMO is inefficiency of determining the signs of ventricular recovery. On patients that are separated from mechanical support, traditional echocardiography and oxygen transfer markers are used. In recent years, myocardial tissue Doppler, with its precision to indicate ventricular improvement, is used in evaluating myocardial function (Cheung \& Redington, 2004).

Patients with myocarditis can be separated after 2 weeks of mechanical support. These patients will immediately show signs of recovery. If separation from the support (weaning) is inefficient and if the patient is a transplant candidate, the mechanical support must resume as a treatment for bridging to transplantation (Duncan et al., 2001). Besides, there can be limiting factors such as availability of the appropriate mechanical assist device to match the heart of the donor.

In some patients with cardiomyopathy, after 2-3 week period, adequate ventricular improvement of ECMO weaning had been detected. These patients are put into transplant list and a very close follow-up is done (McMahon et al., 2003).

Although there is an increase in the number of pediatric ECMO applications, it is disappointing that the survival rate still remains at $40 \%$ for postcardiotomy patients who have undergone mechanical support (ECLS Registry, 2005). When we take a look at the survival rates, we can see some positive changes, if the support is started in semi-elective circumstances during cardiac arrest. The changes are independent from the usage of mechanical support (Del Nido et al., 1999; Morris et al., 2004). After weaning from assist device, the improvement of low cardiac output that is associated with patients with multi organ failure, neurological complications ensue before ECMO procedure starts (Hintz et al., 2005).

In spite of optimal medical treatment, left ventricular assist devices have not been successful on patients with multi-organ failure. Therefore, with the semi-elective implantation of VAD applications, better results are expected for bridging to transplantation than that of resuscitative implantation. Patients that are expected to undergo left VAD implantation, some cardiac and non-cardiac factors must be analyzed thoroughly. Among these, right heart failure is the most important cause of perioperative mortality. During chronic heart failure, pulmonary vascular resistance (PVR) increases. It usually comes back to normal after transplantation or left ventricular assist device implantation. However, on right ventricular failure that develops severe damage due to left ventricular failure, only left VAD implantation requires biventricular support (Kucukaksu et al., 2002).

Left VAD implantation has both desired and unwelcome effects on right ventricle. The most important effect of left VAD on right ventricle is the decrease of afterload and thus the increase of right ventricular output. However, on $20-50 \%$ of patients who are implanted with left VAD, right ventricular dysfunction is developed. Right VAD must be implanted on patients who have developed right ventricular dysfunction. However, if it is spotted early and inotropic agents, pulmonary vasodilators and phosphodiesterase inhibitors are infused, there might not be a need for right VAD. Therefore the early selection of the patients is clinically important. The patients who require left VAD, while waiting for heart transplant, must be assessed carefully in terms of right ventricular failure (Tarcan et al., 2004). 


\section{Costs related to ventricular assist device for pediatric use}

Historically children with severe heart failure had a significant risk of death while awaiting transplantation. However, the overall survival to transplantation with this strategy is less than $50 \%$, and the need for ECMO support before transplantation is associated with poorer posttransplant survival (Boucek et al., 2007). The use of VAD therapy to support children with advanced heart failure has increased in the last several years. This increase is related to several factors, including availability of VAD devices for small children and more favorable outcomes in published series. This present study supports the notion that VAD support allows a significant number of children to survive to either heart transplantation or device explantation. The costs of VAD support are considerable greater than $\$ 500,000$ per initial hospitalization and the calculated incremental cost-effectiveness ratio is high even when compared against most other complex pediatric medical interventions. The cost of VAD support in adults has been intensely studied. Investigators have examined both VAD as a bridge to transplantation and VAD as destination. Analyzing VAD as a destination therapy appears somewhat more favorable (Carrier, 2005).

The study assumes that the quality of life after transplant for children who received VAD support is similar to that of other transplant recipients. However, the occurrence of acute neurologic events such as stroke for children supported with VAD may impact later quality of life. In adults stroke occurs in $25 \%$ of patients supported for 6 months or longer (Tsukui et al., 2007). Limited data from children would suggest that the risk of stroke is the same if not higher than in adults (Malaisrie et al., 2008). Stroke appears to impair children's social ability along with their neurologic function (Lo et al., 2008). The use of pretransplant VAD has been identified with poorer neurologic function in adults after transplantation (Zierer et al., 2007). In addition, it is assumed that children who undergo VAD implantation have equivalent posttransplant survival to those not receiving VAD support.

Follow-up medical costs are substantial, adding to the overall costs. The costliness of VAD support has been a concern for health-policy officials, engendering much debate. The Canadian government initially limited the use of VAD support, concerned that the costeffectiveness was unfavorable (McGregor et al., 2000). The costs of postoperative care will be difficult to modify. One strategy might be to discharge a significant number of children from the hospital so that they might be able to wait at home for an available organ. Certainly, adult centers now have a wealth of experience with home VAD management (Oosterom et al., 2007). Previous investigators have shown that home inotropic medication can be administered safely and inexpensively to children awaiting transplantation (Berg et al., 2007). A shorter waiting time would also reduce overall costs. Lastly, the neurodevelopmental outcome of survivors is largely unknown. Children with VAD support before transplantation may have a significantly poorer quality of life than other pediatric transplant recipients. In summary, using VAD support for children with advanced heart failure permits the majority of children to be bridged to heart transplantation. The costs related to this strategy are relatively high and by some standards exceed the threshold for acceptable cost effectiveness. In light of the rapid pace of evolution in VAD technology one hopes that novel approaches can both improve the outcomes and lower the costs associated with VAD support in children.

\section{Conclusion}

As a summary, the results of patients with myocarditis or cardiomyopathy are highly positive. On patients with myocarditis, if the assist device is used as a treatment for bridging 
to transplantation, the survival rate is $70 \%$ (Acker, 2001). On pediatric population, treatment for mechanical bridging to transplantation has highly successful results. While survival rate with transplantation is $70-80 \%$, successful discharge from the hospital is around $70 \%$ (Goldman et al., 2003; Levi et al., 2002). One of the difficulties that relates to the pediatric population for mechanical support team is that, there are more than one ventricular assist devices in use for neonates and children for long term support. The studies of these pediatric cardiac support devices (PediaFlow VDC, PediPump, PCAS, Pediyatrik Jarvik 2000, TinyPump, TandemHeart, RotaFlow) still continue for future use (Table 4). Ideally, these devices have to be implanted on the patient easily. There is a requirement for advanced technology that allows biologically compatible tube systems without the need of systemic anticoagulation. In addition to this, there must be better techniques that evaluate the ventricular function. This will be a guide to the surgeon in decision making about both starting the mechanical support and weaning from it. CE marking shows that the product has met European standards regarding consumer safety, health or environmental requirements and is an abbreviation for Conformité Européenne (European Conformity). There is not price difference of the VAD in Europe and USA. The price of short term devices is between 8-12.000 $€$, paracorporeal systems $25-50.00 €$ and axial flow systems (double sided) are about $110.000 €$. In recent years, the studies for the manufacture of cardiac support devices in all shapes and sizes still continue to rise. All kind of improvement on this subject is a source of hope for the humankind. The objective for future is to provide permanent solutions.

\section{References}

Acker, M.A. (2001). Mechanical circulatory support for patients with acute-fulminant myocarditis. Ann Thorac Surg; 71:73-6.

Aharon, A.S.; Drinkwater, D.C. Jr; Churchwell, K.B.; Quisling, S.V.; Reddy, V.S. \& Taylor, M. (2001). Extracorporeal membrane oxygenation in children after repair of congenital cardiac lesions. Ann Thorac Surg; 72:2095-101.

Akomea-Agyin, C.; Kejriwal, N.K.; Franks, R.; Booker, P.D. \& Pozzi, M., (1999). Intraaortic balloon pumping in children. Ann Thorac Surg; 67:1415-20.

Ashton, R.C.; Oz, M.C. \& Michler, R.E. (1995). Left ventricular assist device options in pediatric patients. ASAIO J; 41:M277.

Bartlett, R.H.; Gazzaniga, A.B.; Fong S.W.; Jefferies, M.R.; Roohk, H.V. \& Haiduc, N. (1977). Extracorporeal membrane oxygenator support for cardiopulmonary failure. $J$ Thorac Cardiovasc Surg, 73: 375-86.

Bennett, C.C.; Johnson, A.; Field, D.J. \& Elbourne, D. (2001). UK Collaborative ECMO Trial Group. UK collaborative randomised trial of neonatal extracorporeal membrane oxygenation: follow-up to age 4 years. Lancet;357:1094-6.

Berg, A.M.; Snell, L. \& Mahle, W.T. (2001). Home inotropic therapy in children. J Heart Lung Transplant; 26:453-7.

Boucek, M.M.; Aurora, P. \& Edwards, L.B. (2007). Registry of the International Society for Heart and Lung Transplantation: tenth official pediatric heart transplantation report. J Heart Lung Transplant; 26:796-807.

Carrier, M. (2005). Left ventricular assist device: can Canada afford this? Can J Cardiol; 21:1166-8. 
Chaturvedi, R.R.; Macrae, D.; Brown, K.L.; Schindler, M.; Smith, E.C. \& Davis, K.B. (2004). Cardiac ECMO for biventricular hearts after paediatric open heart surgery. Heart; 90: 545-51.

Cheung, M.M.; Redington, A.N., (2004) Assessment of myocardial ventricular function in donor hearts: is isovolumic acceleration measured by tissue Doppler the Holy Grail? J Heart Lung Transpl ;23:253-6.

Darling, E.M.; Kaemmer, D.; Lawson, D.S.; Jaggers, J.J. \& Ungerleider, R.M. (2001). Use of ECMO without the oxygenator to provide ventricular support after Norwood Stage I procedures. Ann Thorac Surg; 71:735-6.

del Nido, P.J.; Armitage, J.M. \& Fricker, F.J. (1994). Extracorporeal membrane oxygenation support as a bridge to pediatric heart transplantation. Circulation; 90:Il66- 9.

del Nido, P.J.; Duncan, B.W.; Mayer, J.E. Jr; Wessel, D.L.; LaPierre, R.A. \& Jonas, R.A. (1999). Left ventricular assist device improves survival in children with left ventricular dysfunction after repair of anomalous origin of the left coronary artery from the pulmonary artery. Ann Thorac Surg ; 67:169-72.

Delius, R.E.; Bove, E.L. \& Meliones, J.N. (1992). Use of extracorporeal life support in patients with congenital heart disease. Crit Care Med; 20: 1216- 22.

Duncan, B.W.; Ibrahim, A.E.; Hraska, V.; del Nido, P.J.; Laussen, P.C. \& Wessel, D.L. (1998). Use of rapid-deployment extracorporeal membrane oxygenation for the resuscitation of pediatric patients with heart disease after cardiac arrest. $J$ Thorac Cardiovasc Surg; 116: 305-11.

Duncan, B.W.; Hraska, V.; Jonas, R.A.; Wessel, D.L.; Del Nido, P.J. \& Laussen, P.C. (1999). Mechanical circulatory support in children with cardiac disease. J Thorac Cardiovasc Surg; 117: 529-42.

Duncan, B.W., (2001) Extracorporeal membrane oxygenation for children with cardiac disease. In: Duncan, B.W. Mechanical support for cardiac and respiratory failure in pediatric patients. New York: Marcel Dekker, 1-20.

Duncan, B.W.; Bohn, D.J.; Atz, A.M.; French, J.W.; Laussen, P.C. \& Wessel, D.L. (2001). Mechanical circulatory support for the treatment of children with acute fulminant myocarditis. J Thorac Cardiovasc Surg; 122: 440-8.

ECLS Registry Report, (2005), International Summary, July 2005; Ann Arbor, MI, USA.

Field, D.; Davis, C.; Elbourne, D., (1996) UK collaborative randomized trial of neonatal extracorporeal membrane oxygenation. Lancet; 348: 75-82.

Goldman, A.P.; Kerr, S.J.; Butt, W.; Marsh, M.J.; Murdoch, I.A. \& Paul, T. (1997). Extracorporeal support for intractable cardiorespiratory failure due to meningococcal disease. Lancet; 349: 466-9.

Goldman, A.P.; Cassidy, J.; de Leval, M.; Haynes, S.; Brown, K. \& Whitmore, P. (2003). The waiting game: bridging to paediatric heart transplantation. Lancet; 362: 1967-70.

Haines, N.M.; Rycus, P.T.; Zwischenberger, J.B.; Bartlett, R.H. \& Undar, A. (2009). Extracorporeal Life Support Registry Report 2008: neonatal and pediatric cardiac cases. ASAIO, J.; 55: 111-6.

Hetzer, R.; Loebe, M. \& Potapov, E.V. (1998). Circulatory support with pneumatic paracorporeal ventricular assist device in infants and children. Ann Thorac Surg; 66: 1498- 506.

Hintz, S.R.; Benitz, W.E.; Colby, C.E.; Sheehan, A.M.; Rycus, P. \& Van Meurs, K.P. (2005). Utilization and outcomes of neonatal cardiac extracorporeal life support: 19962000. Pediatr Crit Care Med; 6: 33-8. 
Hunkeler, N.M.; Canter, C.E.; Donze, A. \& Spray, T.L. (1992). Extracorporeal life support in cyanotic congenital heart disease before cardiovascular operation. Am J Cardiol; 69: 790- 3.

Jaggers, J.J.; Forbess, J.M.; Shah, A.S.; Meliones, J.N.; Kirshbom, P.M. \& Miller, C.E. (2000). Extracorporeal membrane oxygenation for infant postcardiotomy support: significance of shunt management. Ann Thorac Surg; 69: 1476-83.

Kang, N.; de Leval, M.R.; Elliott, M.; Tsang, V.; Kocyildirim, E. \& Sehic, I. (2004). Extending the boundaries of the primary arterial switch operation in patients with transposition of the great arteries and intact ventricular septum. Circulation; 110: 123-7.

Karimova, A.; Robertson, A.; Cross, N.; Smith, L.; O'callaghan, M. \& Tuleu, C. (2005). A wetprimed ECMO circuit with hollow-fiber membrane oxygenator maintains adequate function for use during CPR after 2 weeks on stand-by. Crit Care Med; 33: 1572-6.

Karl, T.R.; Iyer, K.S.; Sano, S. \& Mee, R.B, (1990). Infant ECMO cannulation technique allowing preservation of carotid and jugular vessels. Ann Thorac Surg; 50:488-9.

Karl, T.R.; Horton, S.B. (2001). Centrifugal pump ventricular assist device in pediatric cardiac surgery. In: Duncan BW, editor. Mechanical support for cardiac and respiratory failure in pediatric patients. New York' Marcel Dekker; p. 21-47.

Kato, J.; Seo, T.; Ando, H.; Takagi, H. \& Ito, T. (1996). Coronary arterial perfusion during venoarterial extracorporeal membrane oxygenation. J Thorac Cardiovasc Surg; 111: 630-6.

Konertz, W.F. (2001). Clinical applications in children of the Medos ventricular assist device. In: Duncan BW. Mechanical support for cardiac and respiratory failure in pediatric patients. New York: Marcel Dekker, 269-85.

Korfer, R.; El-Banayosy, A. \&Arusoglu, L. (2000). Single-center experience with the Thoratec ventricular assist device. J Thorac Cardiovasc Surg; 119: 596-600.

Kucukaksu, S.; Şener, E. \& Tasdemir, O. (2002). Bridging to heart transplantation by mechanical assist systems: patient and device selection. Turkish Journal of Thoracic and Cardiovascular Surgery; 10: 190-200.

Langley, S.M.; Sheppard, S.B.; Tsang, V.T.; Monro, J.L. \& Lamb, R.K. (1998). When is extracorporeal life support worthwhile following repair of congenital heart disease in children? Eur J Cardiothorac Surg; 13: 520-5.

Levi, D.; Marelli, D.; Plunkett, M.; Alejos, J., Bresson, J. \& Tran, J. (2002). Use of assist devices and ECMO to bridge pediatric patients with cardiomyopathy to transplantation. $J$ Heart Lung Transpl; 21:760-70.

Lo, W.; Zamel, K. \& Ponnappa, K. (2008). The cost of pediatric stroke care and rehabilitation. Stroke; 39: 161-5.

Malaisrie, S.C.; Pelletier, M.P. \& Yun, J.J. (2008). Pneumatic paracorporeal ventricular assist device in infants and children: initial Stanford experience. J Heart Lung Transplant; 27: $173-7$.

McBride, L.R.; Naunheim, K.S.; Fiore, A.C.; Moroney, D.A. \& Swartz, M.T. (1999). Clinical experience with 111 Thoratec ventricular assist devices. Ann Thorac Surg; 67: 1233-9.

McGregor, M. (2000). Implantable ventricular assist devices: is it time to introduce them in Canada? Can J Cardiol; 16: 629-40.

McMahon, A.M.; van Doorn, C.; Burch, M.; Whitmore, P.; Neligan, S. \& Rees, P. (2003). Improved early outcome for end-stage dilated cardiomyopathy in children. J Thorac Cardiovasc Surg; 126: 1781-7. 
Merkle, F.; Boettcher, W.; Stiller, B. \& Hetzer, R. (2003). Pulsatile mechanical cardiac assistance in pediatric patients with the Berlin heart ventricular assist device. J Extracorpor Technol; 35: 115-20.

Morales, D.L.; Dibardino, D.J. \& McKenzie, E.D. (2005). Lessons learned from the first application of the DeBakey VAD Child: an intracorporeal ventricular assist device for children. J Heart Lung Transplant ; 24: 331- 7.

Morris, M.C.; Ittenbach, R.F.; Godinez, R.I.; Portnoy, J.D.; Tabbutt, S. \& Hanna, B.D. (2004). Risk factors for mortality in 137 pediatric cardiac intensive care unit patients managed with extracorporeal membrane oxygenation. Crit Care Med; 32: 1061-9.

Morris, M.C.; Wernovsky, G. \& Nadkarni, V.M. (2004). Survival outcomes after extracorporeal cardiopulmonary resuscitation instituted during active chest compression following refractory in hospital pediatric cardiac arrest. Pediatr Crit Care Med; 5: 440-6.

Oosterom, A.; de Jonge, N. \& Kirkels, J.H. (2007). End-stage heart failure and mechanical circulatory support: feasibility of discharge from hospital. Neth Heart J; 15: 45-50.

Pizarro, C.; Davis, D.A.; Healy, R.M.; Kerins, P.J. \& Norwood, W.I. (2001). Is there a role for extracorporeal life support after stage I Norwood? Eur J Cardiothorac Surg; 19: 294301.

Pollock, J.C.; Charlton, M.C.; Williams, W.G.; Edmonds, J.F. \& Trusler, G.A. (1980). Intraaortic balloon pumping in children. Ann Thorac Surg, 29: 522-8.

Pychynska-Pokorska, M.; Moll, J.J.; Krajewski, W. \& Jarosik, P. (2004). The use of recombinant coagulation factor VIIa in uncontrolled postoperative bleeding in children undergoing cardiac surgery with cardiopulmonary bypass. Pediatr Crit Care Med; 5: 246-50.

Raithel, R.C.; Pennington, D.G.; Boegner, E.; Fiore, A. \& Weber, T.R. (1992). Extracorporeal membrane oxygenation in children after cardiac surgery. Circulation; 86 (suppl II): II 305-10.

Ratcliffe, M.B.; Bavaria, J.E.; Wenger, R.K.; Bogen, D.K. \& Edmunds, L.H. (1991). Left ventricular mechanics of ejecting, postischemic hearts during left ventricular circulatory assistance. J Thorac Cardiovasc Surg; 101: 245-55.

Reinhartz, O.; Keith, F.M.; El-Banayosy, A.; McBride, L.R.; Robbins, R.C. \& Copeland, J.G. (2001). Multicenter experience with the Thoratec ventricular assist device in children and adolescents. J Heart Lung Transpl; 20:439-48.

Reinhartz, O.; Stiller, B.; Eilers, R. \& Farrar, D.J. (2002). Current clinical status of pulsatile pediatric circulatory support. Am Soc Artific Intern Organs J; 48: 455-9.

Shum-Tim, D.; Duncan, B.W.; Hraska, V.; Friehs, I.; Shin'oka, T. \& Jonas, R.A. (1997). Evaluation of a pulsatile pediatric ventricular assist device in an acute right heart failure model. Ann Thorac Surg; 64: 1374- 80.

Song, X.; Throckmorton, A.L.; Untaroiu, A.; Patel, S.; Allaire, P.E. \& Wood, H.G. (2003). Axial flow blood pumps. Am Soc Artific Intern Organs J; 49: 355-64.

Stiller, B.; Lemmer, J. \& Merkle, F. (2004). Consumption of blood products during mechanical circulatory support in children: comparison between ECMO and a pulsatile ventricular assist device. Intensive Care Med; 30: 1814-20.

Stiller, B.; Weng, Y. \& Hubler, M. (2005). Pneumatic pulsatile ventricular assist devices in children under 1 year of age. Eur J Cardiothorac Surg; 28: 234-9.

Tarcan, O.; Ozatik, M.A.; Kucuker, S.; Askın, G.; Tufekcioglu, O. \& Kucukaksu, S. (2004). The importance and impact of right ventricular functions in left ventricular assist 
device implantation: case report. Turkish Journal of Thoracic and Cardiovascular Surgery; 12: 191-3.

Thuys, C.A.; Mullaly, R.J.; Horton, S.B.; O'Connor, E.B.; Cochrane, A.D. \& Brizard, C.P. (1998). Centrifugal ventricular assist in children under 6 kg. Eur J Cardiothorac Surg; 13: $130-4$.

Tsukui, H.; Abla, A. \& Teuteberg, J.J. (2007). Cerebrovascular accidents in patients with a ventricular assist device. J Thorac Cardiovasc Surg; 134: 114 -23.

Ungerleider, R.M.; Shen, I.; Burch, G.; Butler, R. \& Silberbach, M. (2004). Use of routine ventricular assist following the first stage Norwood procedure. Cardiol Young; 14: 61-4.

Veasy, J.G.; Blalock, R.C; Orth, J.L. \& Boucek, M.M. (1983) Intraaortic balloon pumping in infants and children. Circulation; 1983; 5: 330-3.

Zierer, A.; Melby, S.J. \& Voeller, R.K. (2007). Significance of neurologic complications in the modern era of cardiac transplantation. Ann Thorac Surg; 83: 1684 -90. 


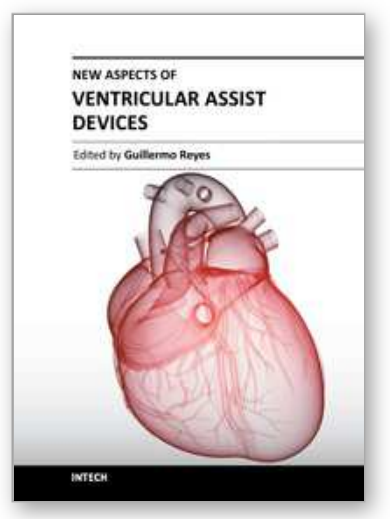

\author{
New Aspects of Ventricular Assist Devices \\ Edited by Dr. Guillermo Reyes
}

ISBN 978-953-307-676-8

Hard cover, 134 pages

Publisher InTech

Published online 29, August, 2011

Published in print edition August, 2011

Ventricular assist device has become one of the standard therapies for the support and the management of the failing heart. Updating our knowledge about these devices is mandatory in order to improve patient outcomes. In this book we can read the efforts made by many physicians concerned with the treatment of heart failure with mechanical devices. We all hope that the information compiled by experts in ventricle assist devices in this book will help us all to do better our main task - heal patients.

\title{
How to reference
}

In order to correctly reference this scholarly work, feel free to copy and paste the following:

Cenk Eray Yildiz (2011). Ventricular Assist Devices for Pediatric Heart Disease, New Aspects of Ventricular Assist Devices, Dr. Guillermo Reyes (Ed.), ISBN: 978-953-307-676-8, InTech, Available from: http://www.intechopen.com/books/new-aspects-of-ventricular-assist-devices/ventricular-assist-devices-forpediatric-heart-disease

\section{INTECH}

open science | open minds

\section{InTech Europe}

University Campus STeP Ri

Slavka Krautzeka 83/A

51000 Rijeka, Croatia

Phone: +385 (51) 770447

Fax: +385 (51) 686166

www.intechopen.com

\section{InTech China}

Unit 405, Office Block, Hotel Equatorial Shanghai

No.65, Yan An Road (West), Shanghai, 200040, China 中国上海市延安西路65号上海国际贵都大饭店办公楼 405 单元

Phone: +86-21-62489820

Fax: $+86-21-62489821$ 
(C) 2011 The Author(s). Licensee IntechOpen. This chapter is distributed under the terms of the Creative Commons Attribution-NonCommercialShareAlike-3.0 License, which permits use, distribution and reproduction for non-commercial purposes, provided the original is properly cited and derivative works building on this content are distributed under the same license. 